\title{
PANORAMA DOS ACIDENTES DE TRABALHO NO BRASIL
}

\author{
POSSEBOM, Gessieli ${ }^{1}$ \\ ALONÇO, Airton dos Santos ${ }^{2}$
}

RESUMO: Acidente de trabalho é toda eventualidade que ocorra e que interrompa parcial ou totalmente o desenvolvimento da tarefa, sendo então de extrema importância que seja evitado. Assim, o objetivo do estudo foi avaliar os acidentes de trabalho ocorridos nos últimos anos no Brasil, considerando diferentes setores econômicos, bem como os membros do corpo humano mais afetado por tal ocorrência. Com base em dados da previdência social, o Brasil registrou 717.911 acidentes (acréscimo de 0,55\% em relação a 2012). Entretanto o número de óbitos reduziu consideravelmente desde o ano de 2000. No panorama de acidentes, a região Sul é a líder no ranking de acidentados por 100 mil habitantes. Os membros superiores são os mais afetados pelos acidentes (quase 50\% do total) e as lesões na coluna vertebral também merecem destaque com 5,03\% do total. Na distribuição por setores econômicos, a indústria lidera com maiores índices de acidentes, seguido pela agropecuária e por fim os serviços. A maioria desses acidentes podem ser evitar com o uso adequado de EPIs, atenção e cuidado na realização da tarefa.

Palavras-Chave: LER. DORT. Membros do corpo. Setor econômico.

SUMMARY: Accident at work is any eventuality that occurs and that partially or totally interrupted the development of the task, and it is of extreme importance that it is avoided. Thus, the objective of the study was elaborated for the cases of work accidents in the last years in Brazil, considering the different economic sectors, as well as the members of the human body and affected by such occurrence. Based on social security data, Brazil recorded 717,911 accidents (up $0.55 \%$ over 2012). There is no panorama of accidents, a South region is a leader without classification of accidents by 100 million inhabitants. The members are most affected by accidents (almost $50 \%$ of the total) and spinal injuries also deserve prominence with $5.03 \%$ of the total. In the distribution by economic sectors, an industry with higher accident rates, followed by agriculture and cattle ranching and services. Most accidents can be used with the use of PPE, attention and care at the time of the task.

Keywords: LER. DORT. Body members. Economic sector

\section{INTRODUÇÃO}

O desenvolvimento tecnológico é um processo que vem se intensificando nas últimas décadas no meio rural. Máquinas, ferramentas e técnicas agrícolas passaram a ser protagonistas no campo, com a intenção de elevar a produtividade aliada a menor utilização de mão-de-obra. Concomitante a isso, a preocupação com a saúde e segurança dos trabalhadores também se elevou, porém ainda assim podem ocorrer acidentes.

Segundo o artigo 131 do Decreto $\mathrm{n}^{\circ} 2.172$, de 05 de março de 1997, acidente de trabalho é o que ocorre na realização do trabalho, a serviço do empregador, provocando lesão corporal, perturbação funcional ou doença que cause a morte ou redução permanente ou temporária da capacidade para o trabalho. Entretanto, segundo UNESP (1994), o acidente de trabalho pode ser considerado como sendo todo acontecimento que não esteja programado e que interrompa, por pouco ou muito tempo, a realização de um serviço, provocando perda de tempo, danos materiais e/ou lesão corporal.

Segundo a Organização Internacional do Trabalho - OIT, em comparação ao meio ambiente, a

\footnotetext{
${ }^{1}$ Doutoranda em Engenharia Agrícola - Universidade Federal de Santa Maria

${ }^{2}$ Professor do Departamento de Engenharia Rural - Universidade Federal de Santa Maria
} 
situação rural é mais grave, pois as pessoas trabalham de forma autônoma, com menor preocupação com a segurança e quando tem ocorrência de acidentes, nem sempre é registrado. Além disso, o trabalho rural é significativamente mais perigoso que outras atividades, estando esses trabalhadores constantemente expostos a fatores como força, repetitividade, postura inadequada, vibração, ruído, ferramentas perigosas, temperaturas extremas e ainda jornada de trabalho intensa, impondo dificuldades à sua realização (ALVES, 2004).

O estudo desses fatores se torna complexo na medida em que seus efeitos não são os mesmos em todas as pessoas, podendo variar ainda de acordo com a intensidade do seu uso, assim como a localidade do corpo em que é afetada. Quando inadequado, o trabalho pode causar desde leves desconfortos; doenças ocupacionais, como as Doenças Osteomusculares Relacionadas ao Trabalho (DORT) ou Lesão por Esforço Repetitivo (LER); à graves acidentes com o trabalhador, bem como alterações psicossociais que são atribuídas ao trabalho (OLIVEIRA, 2009).

Assim, visto a importância que os acidentes representam, o presente estudo teve por objetivo avaliar os acidentes de trabalho ocorridos nos últimos anos no Brasil, considerando diferentes setores econômicos, bem como os membros do corpo humano mais afetado por tal ocorrência.

\section{MATERIAL E MÉTODO}

Os dados levantados foram obtidos através do Ministério do Trabalho e da previdência social. Para tanto, considerou-se as últimas estatísticas disponibilizadas, referente ao ano de 2013, analisando a totalidade de acidentes de trabalho ocorridos no Brasil, bem como as principais consequências desses acidentes para os trabalhadores. Além disso, tendo por base a disposição dos acidentes por regiões do país, avaliou-se comparativamente a situação da região Sul em relação ás demais.

Os acidentes, quando apresentados pelas estatísticas do Ministério do Trabalho, seguem a classificação internacional de doenças (CID), distribuídos em 200 códigos pré-definidos, separados por situação de registro (com comunicado de acidente de trabalho (CAT) e sem CAT) e modalidade (típico, de trajeto e doença do trabalho). A fim de simplificar tais dados, agrupou-se os códigos em grupos mais abrangentes com os principais acidentes e lesões, mantendo separados apenas em ocorrências sem CAT e com CAT.

\section{RESULTADO E DISCUSSÃO}

\section{Panorama geral}

A Organização Internacional do Trabalho - OIT estima que 2,34 milhões de pessoas morrem a cada ano em acidentes de trabalho e doenças, indicando que cerca de 2 milhões dessas mortes seriam causadas por doenças relacionadas com trabalho (Safety and Health in the Use of Chemicals at Work, 2014).

Segundo dados do último levantamento do Ministério do Trabalho (2013), o Brasil registrou 717.911 acidentes (acréscimo de 0,55\% em relação a 2012). Esse aumento ocorreu especialmente após o ano de 2004 e se deve em parte a iniciação da contagem de acidentes trabalhistas sem o CAT, ocorrida a partir desse período. Ainda, essa elevação é atribuída à melhora na notificação e mudanças no critério para caracterização do nexo entre o acidente ou doença e o trabalho, especialmente a partir de 2007 - quando a 
Previdência passou a conceder benefícios relacionados a acidentes e doenças do trabalho mesmo sem CAT registrada, identificando-os pelo tipo de profissão ou trabalho, pelo Nexo Técnico Epidemiológico Previdenciário - NTEP ou Nexo Técnico por Doença Equiparada a Acidente de Trabalho - NTDEAT.

Como consequência dos acidentes ocorridos, em 2013, números igualmente alarmantes de trabalhadores mortos (2.797), incapacitados temporários (610.804), incapacitados permanentes para o exercício profissional (14.837) e que receberam assistência médica (108.940). Há que se ressaltar que, embora o número de óbitos ainda seja alto no último ano levantado, as taxas de mortalidade por acidentes do trabalho no Brasil têm decrescido desde o início dos anos 2000 (Figura 1), em razão da ampliação da população segurada em consequência da acentuada elevação dos níveis de emprego (BRASIL, 2016).

Essa estatística é de extrema importância pois apesar do número total de acidentados ter se elevado, retrata que a gravidade desses acidentes e que, portanto, resultam em morte, foi reduzida. A inserção de tecnologias no sistema de trabalho, bem como qualificação dos profissionais podem ser a causa dessa redução de óbitos tão importante.

Figura 1:Taxa de Mortalidade por acidentes e doenças do trabalho, 1997-2013 (por 100 mil habitantes segurados).

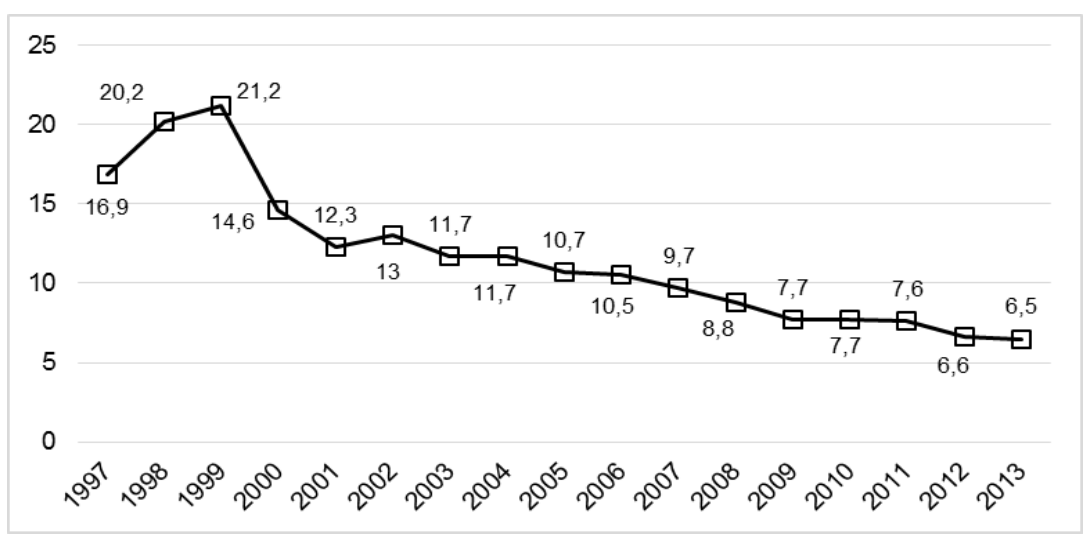

Fonte: BRASIL (2016).

Nesse panorama, no mesmo ano, a região Sul assumiu a segunda posição no ranking de acidentados, com 158.113 casos (22,02\% do total nacional) e 547 mortes (19,56\% do total nacional), apresentando elevação de $0,92 \%$ no índice de óbito, em comparação ao ano anterior. Entretanto, conforme pode ser observado no Quadro 1, quando analisado a relação de acidentes com o número de trabalhadores, a região Sul toma o topo do ranking com 1.879 casos, ficando a cima da média nacional que é de 1.467 acidentados por 100 mil trabalhadores.

Quadro 1: Número de acidentes e trabalhadores, comparativamente por regiões do Brasil, no ano de 2013.

\begin{tabular}{|c|c|c|c|}
\hline Regiões & Trabalhadores & Total de acidentes & Acidentes/100 mil trabalhadores \\
\hline Brasil & 48.948 .433 & 717.911 & 1.467 \\
\hline Norte & 2.743 .248 & 31.275 & 1.140 \\
\hline Nordeste & 8.926 .710 & 86.225 & 966 \\
\hline Sudeste & 24.623 .001 & 390.911 & 1.588 \\
\hline Sul & 8.415 .302 & 158.113 & 1.879 \\
\hline Centro-Oeste & 4.240 .172 & 51.387 & 1.212 \\
\hline
\end{tabular}

Fonte: BRASIL (2016). 
A primeira consequência dos acidentes é a ausência do trabalhador no posto de trabalho, comprometendo a tarefa que por ele vinha sendo desempenhada, entretanto em se tratando de trabalho, esse efeito é imediatamente sanado com a substituição por outro empregador. Porém são incalculáveis os prejuízos que decorrem desses infortúnios, tanto para as famílias das vítimas como para as empresas e a Previdência Social. Perdas financeiras com a concessão de benefícios acidentários, redução da produtividade e vidas precocemente interrompidas pelas más condições de saúde e segurança no ambiente laboral são os danos mais visíveis de uma realidade na qual os indicadores negativos avançam quando deveriam recuar.

\section{Membros do corpo mais atingidos}

A ocorrência de uma grande variedade de acidentes pode consequentemente, afetar diferentes partes do corpo humano. Existem atividades que exigem de forma mais intensa alguns membros específicos, bem como outras que necessitam da interação de várias partes do corpo, acarretando, quando da ocorrência de acidentes, em um número maior de membros envolvidos.

A Figura 2 apresenta os principais grupos de acidentes, ocorridos no Brasil, de acordo com as partes do corpo atingidos. Observa-se que do total de 158.113 casos, 47,09\% são acidentes envolvendo membros superiores e apenas $22,61 \%$ se relacionam a membros inferiores. Os membros superiores são exigidos de forma mais elevada no desenvolvimento de diversas atividades, uma vez quena maioria das vezes, são os primeiros órgãos em contato direto com as ferramentas ou máquinas, estando assim mais suscetível a acidentes.

Além disso, quando se trata de produção em série, as atividades exigem alta repetitividade e monotonia de movimentos, especialmente envolvendo mãos e punhos, ficando os trabalhadores condicionados a elevadas jornadas de trabalho e ao não uso de pausas frequente. Ou seja, quando a intensidade de fatores causadores de lesão é maior que a capacidade de recuperação do organismo, o resultado é a ocorrência de acidentes e lesões no corpo (COUTO, 2007).

Em comparação aos membros superiores, os índices de acidentes relacionados a membros inferiores são de menor grau, devido a menor exposição que sofrem no desenvolvimento das atividades. Entretanto, esse tipo de acidentes, especialmente na região das pernas é justificado por grandes distâncias que os trabalhadores necessitam percorrer, por vezes em terrenos acidentados ou com obstáculos. Além disso, algumas atividades exigem que os trabalhadores assumam posições agachadas, como é o caso por exemplo em atividades em viveiro florestal (POSSEBOM, 2017). Essas, quando em uso frequente, são inadequadas pois não proporcionam conforto e apoio necessário para as pernas no momento da execução da tarefa, podendo causar dor e desconforto aos trabalhadores.

Apesar dos membros superiores e inferiores serem os mais atingidos pelos acidentes (Figura 2), $5,03 \%$ da totalidade de acidentes, se relacionam com a região da coluna. Esse valor é extremamente elevado se comparado a porcentagem envolvendo as lesões de todas as demais regiões do corpo, em que totalizam 5,59\%. Quando uma tarefa é realizada adotando-se posturas inadequadas, pode ocasionar graves consequências para a saúde do trabalhador. 
Figura 2: Porcentagem do total de acidentes, de acordo com os principais registros, no Brasil, no ano de 2013.

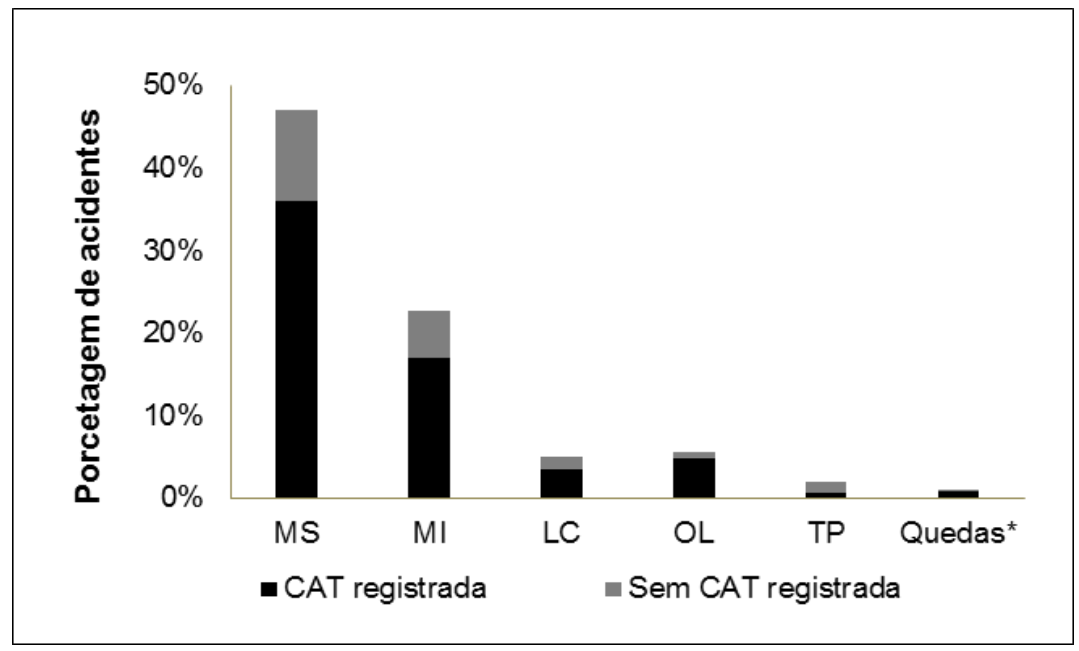

MS: Membros Superiores; MI: Membros Inferiores; LC: Lesões de Coluna; TP: Transtornos Psicossociais. *Quedas/ outros acidentes ou traumatismos por acidentes.

Fonte: Autor.

O carregamento e transporte de peso é indicado como uma das principais causas das lesões ou acidentes relacionados a coluna, isso porque nesses casos geralmente o trabalhador se depara com um viés de duas faces. Por um lado, ao transportar uma quantidade reduzida de peso é necessário realizar um número maior de viagens até o ponto de abastecimento, acarretando perdas de tempo no trabalho e menor eficiência na atividade. Por outro lado, com uma grande quantidade de produto a ser transportado, haverá redução das perdas de tempo, cumprindo a tarefa de forma mais ágil, porém realizando a tarefa de forma mais difícil e exaustiva.

O trabalhador tem a preferência de aumentar a quantidade de peso a ser transportada ao número de viagens, ocasionando grandes danos à saúde, uma vez que o peso aumenta a pressão sobre os ombros, a coluna vertebral e as articulações do corpo. Tarefas de plantio florestal, transporte de materiais e monda, em viveiros, figuram entre as principais causas de dores e consequente lesões e acidentes nas costas e coluna vertebral em trabalhadores rurais (FERREIRA, 2006; ALVES, et al, 2001; SILVEIRA, 2006, BRITO, 2012).

O efeito de carregamento inadequado de peso afeta não somente a coluna vertebral como também é um dos fatores que contribui para o elevado índice de acidentes e lesões nos membros superiores, envolvendo especialmente regiões de braços, antebraços, mãos e punhos, devido a manipulação do material. A NIOSH (National Institute of Occupational Safetyand Health) recomenda o peso de $23 \mathrm{~kg}$ como limite máximo para transporte manual de forma que não cause desconforto nos trabalhadores. A maior força de compressão no disco da coluna vertebral tem relação direta com a postura adotada pelos trabalhadores, pois esta é considerada mais nociva quanto mais se afasta da posição de neutralidade funcional ou anatômica, podendo assim provocar doenças ocupacionais e lesões (COUTO, 2007).

Merece destaque ainda, os transtornos psicossociais conferidos na Figura 2. Fazem parte desse grupo, quadros de estresse, episódios depressivos, transtornos envolvendo álcool, transtornos mentais, de ansiedade, de bipolaridade, entre outros, totalizando $1,87 \%$ dos acidentes de trabalho. Dentre fatores causadores, a genética, a química cerebral e o estilo de vida são tidos como os principais desencadeadores, por afetarem diretamente o cérebro. Porém por atingir esse órgão, consequentemente podem provocar outras doenças pelo corpo, produzindo sintomas somáticos, como é o caso das dores nas costas, muitas vezes sintoma de um processo depressivo e não de exaustão do profissional (ARANDA, 2016). 
Além das consequências imediatas, as lesões e acidentes ocasionam efeitos de longo prazo, como: fadiga muscular crônica, sobrecarga imposta ao aparelho respiratório, formação de edemas, varizes e problema nas articulações. As lombalgias não só afetam a saúde do próprio trabalhador como também existem consequências sociais, como absenteísmo, mudança de profissão por incapacidade laboral e gastos previdenciários, entre outros que não devem ser negligenciados (MERINO, 1996).

\section{Estatísticas no meio rural}

Segundo o Ministério do Trabalho, as atividades econômicas podem ser divididas em três diferentes setores, sendo eles: a indústria, serviços e agropecuária. Apesar dos índices de acidentes trabalhistas totais terem apresentado um acréscimo no último ano, como observado anteriormente, essa realidade felizmente não é notada quando analisado o número de acidentes em 100 mil trabalhadores independente do setor de trabalho considerado.

O acréscimo de acidentes totais e redução de acidentados por 100 mil habitantes pode ser decorrente do aumento da população trabalhista, corroborando tais estatísticas. A distribuição dos acidentes pelos setores econômicos, conforme a Figura 3, demonstra que a indústria apresenta os maiores índices desde o ano de 2008 (3.547 casos) até o último levantamento, ocorrido em 2013, onde apresentou 2.597 casos. Na sequência o setor de agropecuária inicialmente com 2.092 casos, finalizou 2013 com 1.584 acidentados e por fim os serviços que obteve um decréscimo de $15,45 \%$ nos acidentes quando em comparação 2008-2013.

Figura 3: Número de Acidentes/ 100 mil Trabalhadores, divididos por setores no Brasil.

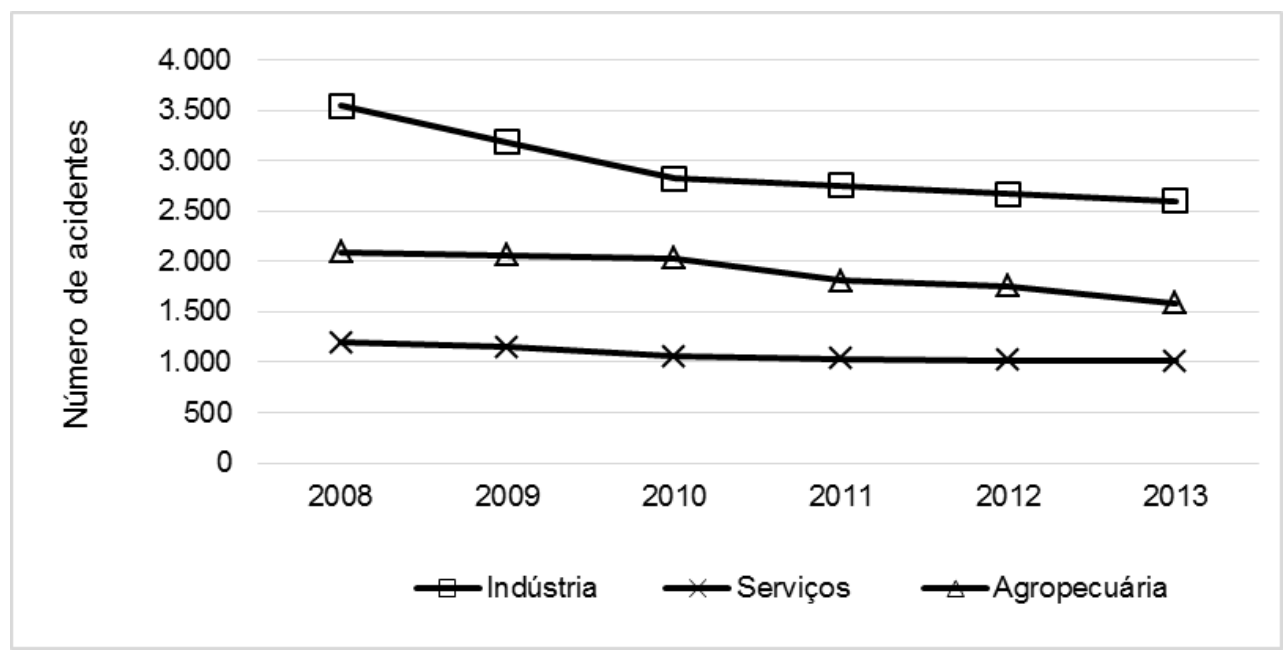

Fonte: BRASIL (2016)

Os acidentes de trabalho, quando da sua ocorrência no meio agropecuário/rural, dentre os três setores, é o que envolve especialmente máquinas e equipamentos agrícolas obsoletos e inseguros. $\mathrm{O}$ principal risco é devido a máquina não conter os dispositivos de segurança necessários e exigidos por lei, para proporcionar proteção básica ao operador. Uma vez sem a mínima segurança, há o perigo de contato de partes do corpo (mãos e dedos, sobretudo) com as ferramentas de corte, o que pode causar esmagamento ou outro tipo de acidente.

As prensas usadas no meio rural foram responsáveis por $36 \%$ dos acidentes seguidos de amputação do total de 196 acidentes graves com máquinas registrados. Em conjunto com esse 
equipamento, as serras, as guilhotinas e as máquinas para madeira, especialmente o uso de motosserras, constituem o grupo de máquinas responsável pela maioria dos acidentes graves (SILVA, 1995).

Segundo o Ministério do Trabalho, muitos são os casos de trabalhadores que operam maquinas que não possuem dispositivos de proteção essenciais ou que adulteram ou mesmo retiram os dispositivos de proteção de equipamentos e máquinas com o intuito de facilitar a atividade, e consequentemente coloca em risco a sua segurança. Ainda, existem trabalhadores que operam máquinas sem realizar a devida manutenção, e por vezes sem o treinamento adequado para manipular os equipamentos. Esses fatores isolados ou em conjunto são agravantes para a ocorrência de acidentes de trabalho.

É mais grave ainda o problema se considerar que a imensa maioria desses acidentes, na verdade, podem perfeitamente ser prevenidos ou evitados. Após a consolidação das leis do trabalho (CLT), todas as empresas são obrigadas a fornecerem a seus funcionários os equipamentos de proteção individual de acordo com a função desempenhada e seus riscos. O fortalecimento das leis trabalhistas aliada a intensificação da fiscalização, são fatores importantes para essa redução dos acidentes.

Entretanto, a consciência de que é necessário cuidado ao realizar as tarefas, assim como treinamento de qualidade são essenciais para prevenir a ocorrência de acidentes de trabalho. Utilizar equipamentos adequados com a função desempenhada e em bom estado são de mesmo modo cruciais para o bom desempenho do grupo de trabalho. A adoção dessas medidas simples, mas muito importantes contribuem para a diminuição dos acidentes de trabalho.

\section{CONCLUSÃO}

O número de acidentes trabalhistas apresentou um acréscimo nos últimos anos analisado quando comparado aos demais, entretanto casos sem CAT foram inseridos ao cálculo. No panorama nacional, a região Sul ficou em segundo lugar no número de acidentados e assume a liderança do ranking em se tratando de acidentes em 100 mil trabalhadores.

Em relação aos membros do corpo mais afetados por lesões e acidentes, destacam-se os membros superiores e coluna vertebral. Na análise por setor de atividades, a ordem decrescente de casos de acidentes ficou em: indústria, agropecuária e serviços, e todos os setores apresentaram redução dos casos de acidentes em 100 mil habitantes desde o ano de 2008.

Os acidentes no meio rural envolvem especialmente máquinas e equipamentos agrícolas. Para sua prevenção é crucial uso de EPI's adequados, além da consciência de cautela e atenção durante a atividade.

\section{REFERÊNCIAS}

ALVES, J. U.et al. Avaliação biomecânica dos trabalhadores nas atividades de propagação de Eucalyptus spp. Ciência Florestal, Santa Maria, v.11, p.81-91, 2001.

ALVES, J. U. Análise ergonômica da produção de mudas de eucalipto em Viveiro, no Vale do Rio Doce, MG. 2004. 112p. Tese (Doutorado em Ciência florestal) - Universidade Federal de Viçosa.

ARANDA, F. Dor nas costas é a líder de afastamento do trabalho. iG São Paulo. Disponível em: $<$ http://saude.ig.com.br/minhasaude/dor-nas-costas-e-a-lider-de-afastamento-dotrabalho/n1596821675441.html>. 2016. Acesso em fev. 2017.

BRASIL. Decreto n. 2172 de 05 de março de 1997. Dispõe sobre os benefícios da Previdência Social. Lex: coletânea de legislação, Brasília, DF, p. 23. Disponível em: < http://sislex.previdencia.gov.br/paginas/23/1997/2172.htm>. Acesso em jan. 2017. 
BRASIL. Ministério Do Trabalho. Previdência Social, 2016. Disponível em: <http://www.previdencia.gov.br/>. Acesso em: jan. 2017.

BRITO, P. C. de. Análise de fatores ergonômicos em Atividades de implantação florestal. 2012. 151 p. Dissertação (Mestrado em Ciências Florestais) - Universidade Estadual do Centro-Oeste-UNICENTRO, Irati, PR.

COUTO, H. A. Ergonomia aplicada ao trabalho: conteúdo básico: guia prático. Belo Horizonte: ERGO, 2007.

FERREIRA, P. C. Avaliação ergonômica de algumas operações florestais no município de Santa Bárbara-MG. 2006. 77 p. Dissertação (Mestrado em Meio Ambiente e Sustentabilidade) - Centro Universitário de Caratinga - UNEC, Caratinga, MG.

MERINO, E.A.D. Efeitos agudos e crônicos causados pelo manuseio e movimentação de cargas no trabalhador. 1996. 128p. Dissertação (Mestrado em Engenharia de Produção e Sistemas) - Universidade Federal de Santa Catarina, Florianópolis.

NATIONAL INSTITUTE OF OCCUPATIONAL SAFETY AND HEALTH. Disponível em: <https://www.cdc.gov/niosh/>. Acesso em: 12 jan. 2016.

OLIVEIRA, P. A. B. Ergonomia. In: CATTANI, A. D. (Org.). Trabalho e tecnologia: dicionário crítico. Petrópolis: Vozes, 2009.

OIT- Organização Internacional do Trabalho, 2016. Disponível em: < http://www.ilo.org/brasilia/lang-pt/index.htm>. Acesso em: 10 já 2017.

POSSEBOM, G.et al. Avaliação ergonômica em um viveiro florestal de Santa Maria, RS. Revista Tecnológica, Santa Cruz do Sul, p. 30-36, 2017.

SAFETY and Health in the Use of Chemicals at Work.International Labour Organization, 2014.Disponível em:

<http://www.ilo.org/wcmsp5/groups/public/@ed_protect/@protrav/@safework/documents/publication/wc ms 235085.pdf $>$.

SILVA, L. F. Acidentes de trabalho com máquinas: estudo a partir do sistema de vigilância do programa de saúde dos trabalhadores da Zona Norte de São Paulo, em 1991. 1995. 201 p. Dissertação (Mestrado em Saúde Pública) - Universidade Paulista, São Paulo.

SILVEIRA, F. S. A. Avaliação ergonômica das atividades de coveamento manual, coveamento semi mecanizado, plantio manual e aplicação de corretivo do solo na implantação florestal de eucalipto. 2006. 85 p. Dissertação (Mestrado em Meio Ambiente e Sustentabilidade) - Centro Universitário de Caratinga- UNEC, Caratinga, MG.

UNESP- Universidade Estadual Paulista. Prevenção e controle de riscos em máquinas. Bauru: Faculdade de Engenharia e Tecnologia, 1994. 165p. (Apostila). 